\title{
Global Progress of Perinatal Medicine
}

\section{Kazuo Maeda*}

Department of Obstetrics and Gynecology, Tottori University School of Medicine, Japan

Perinatal state is significant in human life because fetal development during pregnancy is the base of a human, who will develop after the birth to be a great human who will guide the world by its political, scientific, medical and other various field activity. In the dark side of life, however, fetal hypoxia will develop a cerebral palsy in the infants which disturbs motor activity, despite of unaffected intelligence, while a growth restricted fetus will develop various metabolic diseases after grown up, according to the theory of Barker. A preterm immature neonate tends to be disturbed in postnatal development or by neurological sequelae. Several congenital anomaly or aneuploidy develops pathological syndromes after birth. There are many tools to predict fetal anomaly from the early gestation, namely ultrasonic imaging with real-time sonogram, 3D and 4D ultrasound, blood flow studies, ultrasonic tissue characterization, magnetic resonance imaging, magnetocardiogram or magnetoencephalogram, and so on detect various fetal abnormality before the birth, while ante- and intrapartum fetal heart rate monitoring detect fetal hypoxia to reduce fetal and neonatal deaths, and also to reduce neonatal cerebral palsy, as well as to reduce neonatal asphyxia to improve infantile outcome.
Fetoscopic laser therapy cures monochorionic twins from Twin to Twin Transfusion Syndrome (TTTS) disease. Noninvasive powerful focused ultrasound removes hazardous structure in the Twin reversed Arterial Perfusion sequence (TRAP sequence) of monochorionic twins. Antibiotics cured neonates from infectious disease to prolong Japanese life span for 5 years after the introduction of modern medicine; the health of neonates and infants was improved by the establishments of blood supply center, central laboratory and the department of anesthesia in Japan after the II World War. The preterm neonatal deaths reduced after the introduction of artificial surfactant therapy in Japan. These were the progress of a developed country, therefore, the perinatal status will be clearly improved by the vaccination and preventive procedure in general medicine, obstetric strategies, and the medical care in developing or undeveloped country or region. The special issue of the Journal of Health \& Medical Informatics was planned to search what is sufficient and what is insufficient in perinatal medicine in the world countries. Thus, the editor would like to ask to report the past and present status in the perinatal medicine in the world by the prominent professors and doctors in their experience and documents.
*Corresponding author: Kazuo Maeda, Department of Obstetrics and Gynecology, Tottori University School of Medicine, Japan, E-mail: maedak@mocha.ocn.ne.jp

Received November 29, 2012; Accepted November 29, 2012; Published December 03, 2012

Citation: Maeda K (2013) Global Progress of Perinatal Medicine. J Health Med Informat S11:e001. doi:10.4172/2157-7420.S11-e001

Copyright: (c) 2013 Maeda K. This is an open-access article distributed under the terms of the Creative Commons Attribution License, which permits unrestricted use, distribution, and reproduction in any medium, provided the original author and source are credited. 